\title{
Usability and Interaction Design - new challenges for the Scandinavian tradition
}

\author{
SUSANNE BØDKER ${ }^{\dagger}$ AND YNGVE SUNDBLAD ${ }^{*^{*}}$ \\ $\dagger$ Department of Computer Science, University of Aarhus, Denmark \\ ${ }^{\dagger}$ HCI Department, School of Computer Science and Communication, KTH, Stockholm \\ ${ }^{*}$ Corresponding author, email: y@kth.se
}

\begin{abstract}
Computer use and interaction possibilities are changing quickly, while use contexts and application types are radically broadening. Technology no longer consists of static tools belonging only to the workplace, but permeates work on the move, homes and everyday lives. Pervasive technologies, augmented reality, small interfaces, tangible interfaces, etc. are dramatically changing the nature of HCI (human-computer interaction). We witness the creation of ad-hoc configurations of large and small user interfaces. The new interfaces are moveable and used in changing locations and contexts; different tasks are done through a combination of specialized technologies. A wider repertoire of physical instruments is available than the keyboard and the mouse.

Based on examples from recent research projects, and a collage of concepts and solutions we discuss how these recent developments challenge our understanding of usability and interaction design. In particular we discuss how the Scandinavian tradition of user involvement in development is facing up with the challenges of new work and of non-work contexts.
\end{abstract}

There is a tendency that much recent investigations into non-work settings get stuck in a divide between work on the one hand, and leisure, arts, and home on the other; between rationality on the hand, and emotion on the other. The Scandinavian tradition can be developed to embrace people's whole lives and transcend the dichotomies between work, rationality, etc. and their negations and a Scandinavian perspective should and could move the current co-determination framework outside of work.

Keywords: Usability, Human-Computer Interaction, Cooperative design, Scandinavian tradition of development, User involvement, New interfaces, Whole life use

\section{Introduction}

The authors were involved in the 'seminal' Utopia project, 1981-85, where Co-operative Design methodology, involving users very early in the design process, had an early development and application in the use of computers.

One strong goal was to 'give the end users a voice' in design and development of computer support in work places, thus enhancing the quality of the resulting system. The 'secondary result' of Utopia, the methodology, with ingredients such as low-tech prototyping, early design sessions with users etc, has had great impact on IT design in general. This is the case not only where the methods are part of now common practices in HCI and in CSCW in general and in later methodologies such as Contextual Design and Co-operative Inquiry. 
Today the obvious idea to involve the users as early as possible in systems and interface design, using low and high tech prototypes, has become a standard to which most developers pay at least lip service.

In our 25 years of practical experience from several co-operative design and development projects there have been tremendous growth in the spread of IT use, based on technical and organisational developments. At the present time, computer use and interaction possibilities are changing quickly, perhaps more quickly than they have done in the past. At the same time, use contexts and application types are broadening. Technology no longer consists of static tools belonging only to the workplace. They present users with the possibilities of working 24 hours a day, 7 days a week, while on the move, at home and in the public space.

At the same time as work technologies permeates the boundaries between the workplace and human life in general, other technologies seem to expand from home life and leisure into the workplace. Text messages is a classic example and blogs a more recent one. We witness the creation of ad-hoc configurations of large and small user interfaces. The new interfaces are moveable and used in changing locations and contexts; different tasks are done through a combination of specialized technologies. A wider repertoire of physical instruments is available than the keyboard and the mouse. These recent trends of pervasive computing place the user in dynamic configurations of technology, where human activity is not necessarily performed through a single personal computer application but supported by a range of technologies and physical artefacts that are often dynamically changing through mobility. This kind of multiplicity is well-known from everyday artefacts in general: When a pilot is controlling an aircraft, the captain a cargo ship, or the mason is building a house, there is not necessarily one single unified interface between the user and whatever is the object of the activity, be this the safe journey of the aircraft, the optimal route of the cargo ship, or the brick walls of the house. This dynamics is in contrast to how HCI has been focusing on one technology-one application-one user. Often the design ideal for any device seems to be that if the user was stuck on a remote island he would carry all functions and data needed with him.

In this way, pervasive technologies, augmented reality, small interfaces, tangible interfaces, etc. are dramatically changing the nature of human-computer interaction (HCI) as regards its conceptual basis, its design possibilities and its everyday analysis and design methods, issues often connected to usability.

\section{Scandinavian tradition - many projects at work and outside}

In Scandinavia, research projects on participatory design, cooperative design, or user participation in systems development, date back to the 1970s (Bødker 1996). The Norwegian Iron and Metal Workers Union (NJMF) project took a first move from traditional research to working with people, directly changing the role of the union clubs in the project (Ehn \& Kyng 1987), and in general, the tradition has developed strategies and techniques for workers to influence the design and use of computer applications at the workplace.

The projects emphasized the active co-operation between researchers and workers of the organization to help improve their work situation. While researchers got their results, workers were equally entitled to get something out of the project. Methods for involving end users in all phases of design and development of IT support for their activities were in focus with the seminal Utopia project. Graphic workers were involved in building new technology and the project invented methods such as low-tech prototyping, workflow wallpapers, and work organisation toolboxes (Bødker, Ehn, Kammersgaard, Kyng \& Sundblad 1987). Since then the methodology has developed, see (Bødker, Ehn, Sjögren \& Sundblad 2000), and been complemented with a battery of other methods into strategies for involving users for better suited IT support, e.g. scenarios (Kyng 1995; Bødker \& Christiansen 1997), cooperative inquiry (Druin 1999), technical probes (Hutchinson \& al., 2003), video prototyping (Mackay 
\& al 2000), vision games (e.g. Halskov \& Dalsgaard 2006, Hornecker \& Buur 2006), close cooperation with joint user experience between ethnographer, industrial designer and programmer (Westerlund, Mackay, Lindquist \& Sundblad 2003) and overall process design, e.g. Cooperative Experimental Systems Development (Grønbæk \& al. 1997) which combined iterative cycles of general development of technology, and specific participatory design cycles in the two empirical settings, or MUST (Kensing \& al. 1998) which provided an industrial method for the early phases of design.

Starting with graphic workers in Utopia 1981-85, we have been involved in at least 20 research and development projects, involving researchers, designers, programmers and users in cooperative design: office workers, architects, engineers, labour inspectors, teachers at several school levels, metal workers, call centre personnel, tax officers, installation artists, elementary school children, intergenerational family members.

As IT applications expands from the workplace into everyday life in general, participatory design in the Scandinavian tradition is now also used for home and leisure IT applications and for everyday communication situations. This, together with the new, more decentralised and portable forms of and interaction with the technology forms new challenges (see e.g. Beck 2000, Kristensen et al. 2003). These challenges include methods for observational and in-situ studies in people's homes and similarly intimate situations, concern for learning and skilldevelopment outside well-defined work situations, and ways of moving the fundamental focus of human-computer interaction away from efficiency and effectiveness, and towards experience. They are not isolated to the cooperative design tradition (Bødker 2006; Petersen 2004), but stands as challenges to the entire field of HCI, as we shall discuss further below.

\section{New technology for new forms of interaction}

In its early days, the field of human computer interaction was heavily influenced by human factors research and cognitive science, and usability and usability evaluation were often the practical foci of HCI. Influence from cooperative design was significant in the transition from the first to the second generation HCI; the move characterized by Bannon (1986) as "from human factors to human actors." In the second generation (Bødker 2006), focus was on groups working with a collection of applications. Theory focused on work settings and interaction within well-established communities of practice. Situated action, distributed cognition and activity theory were important theoretical sources, and concepts like context came into focus of analysis and design of human-computer interaction. Rigid guidelines, formal methods, and systematic usability testing were abandoned for proactive methods such as a variety of participatory design workshops, prototyping and contextual inquiry (Beyer \& Holtzblatt 1997). These less formal forms of usability testing are often still in use in everyday HCI.

At present use contexts and application types are broadened, and intermixed. Computers are increasingly being used in the private and public spheres. Technology spreads from the workplace to our homes and everyday lives and culture, and this has lead some researchers to propose a third generation or wave (Bødker 2006), that one might identify as a break with the second wave, theoretically and technologically.

New elements of human life are included in the human-computer interaction such as culture, emotion and experience (McCarthy \& Wright 2004), and the focus of the third wave, to some extent, seems to be defined in terms of what the second wave is not: non-work, non-purposeful, non-rational, etc. Methodologically, the third wave has partly moved away from a commitment to users towards a more exploratory take-it-or-leave-it approach (Dunne \& Raby 2001) where designers seek inspiration from use, e.g. through cultural probes. Whereas this is a provocation to cooperative design, the third wave has helped emphasize the need of moving away from usability testing towards early experimentation and design, both seen as an 
aesthetic discipline embracing the virtual as well as e.g. physical form, and as the part of the development that emphasizes the exploration and conception of ideas.

Bødker (2006) discusses how the second and the third wave of HCI may influence one another and how, in particular, cooperative design may have a role in this interplay. The paper argues that the second wave needs to transcend its conceptions of multiplicity and context. At the same time, the third wave must leave the artistic, cultural focus, and the focus on mediators that either make us break down or act transparently, hence embracing learning and cooperation in communities of practice. As a consequence, a true third wave must embrace people's whole lives and transcend the dichotomies between work, rationality, etc. and their negations. Bødker (2006) points out how the emerging third wave seems strongly tied to a kind of consumerism or voting with the feet that differs from the underlying co-determination framework of the Scandinavian societies. She proposes to make use of people's experiences of cooperating and learning, hence supporting them in making informed choices that would transform their lives with technology.

In the following we will present a collage of examples illustrating the challenges that humancomputer interaction is currently facing, and we will sketch and discuss how the examples dealt with the challenges.

\section{A collage of examples}

\subsection{Multiplicity}

We illustrate this with two work situations with mixes of new and old technologies.

The ship bridge (fig.1), (Bødker \& Bøgh Andersen 2005), illustrates how new design becomes part of the many instruments on the bridge at the same time as the old instruments stay. Also it accommodates for changing configurations of actors depending on the situation (e.g. the division of work changes between open water and harbour navigation).

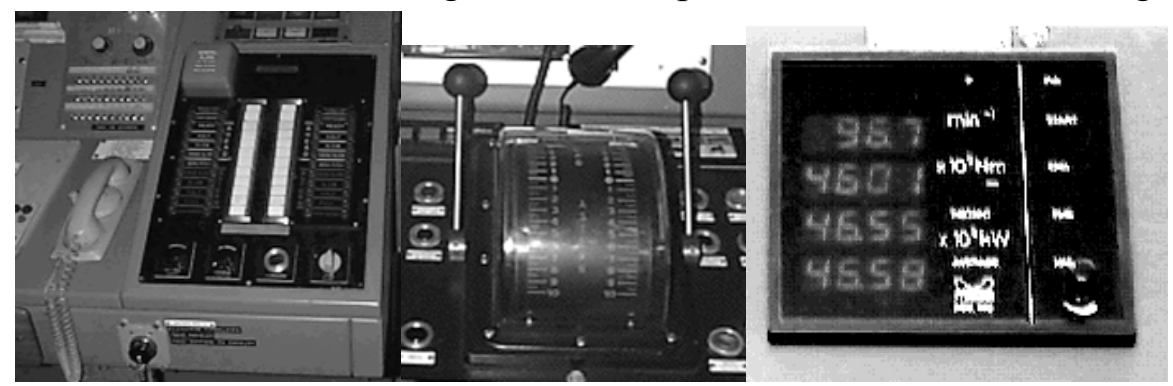

Figure 1 Ship bridge with new and old instruments.
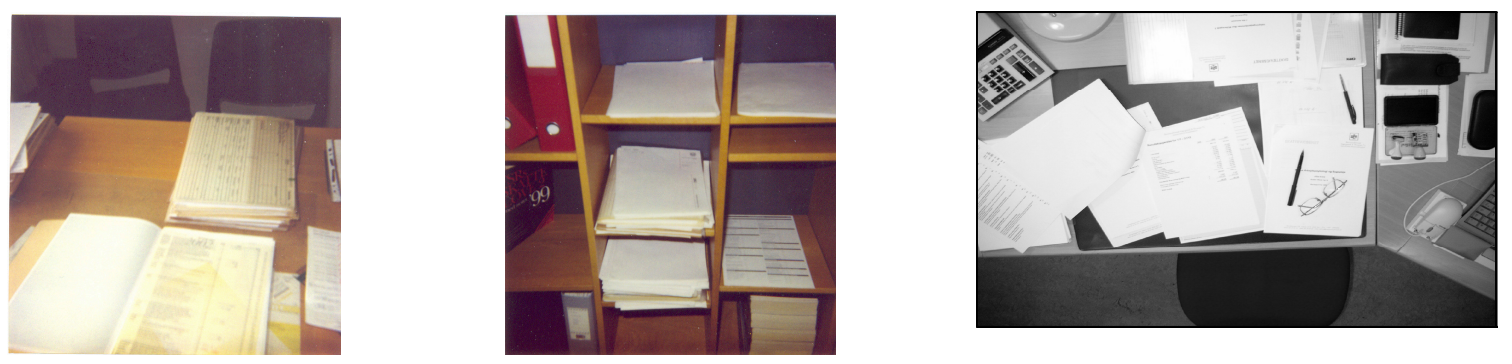

Figure 2 Tax office desks and shelves.

The tax desktop (fig.2), Nielsen \& Bødker (2004), illustrates routines across multiple instruments. It illustrates that the structure and ordering of the background (the desktop) are essential, and how it is necessary to be able to place documents and instruments next to one another in the everyday situation. 


\subsection{Breaking isolated work situations}

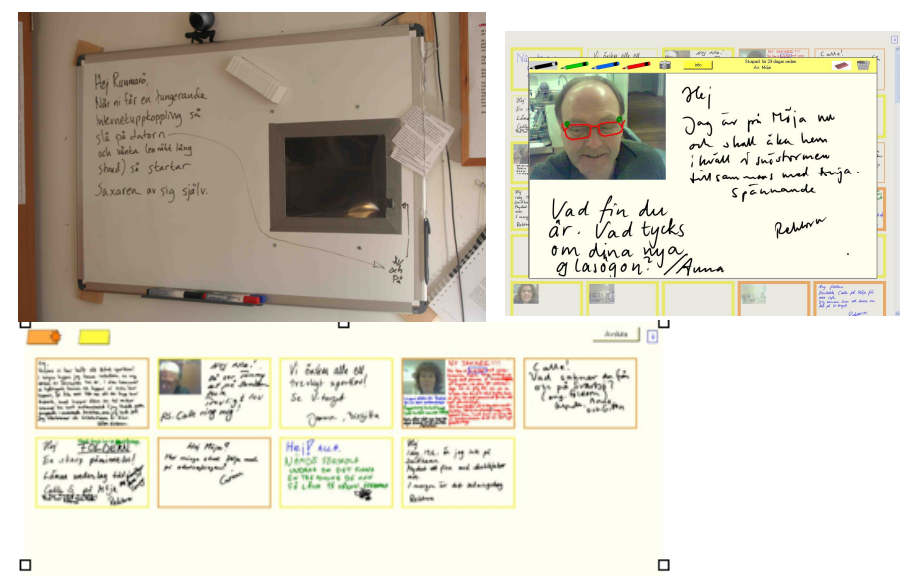

Figure 3. Archipelago teacher communication

By installing a simple to use device (on the whiteboard) for drawing and sending notes to each other, fig.3, the single-working teachers on islands in the Stockholm archipelago could form a community, for work and leisure (Groth \& al 2006)

Work stretches into our everyday life but also vice versa. Experience with technology is a process that is not isolated to singular work situations: it accumulates from school to old age, across life and work, and across work situations.

\subsection{Ad-hoc configuration}
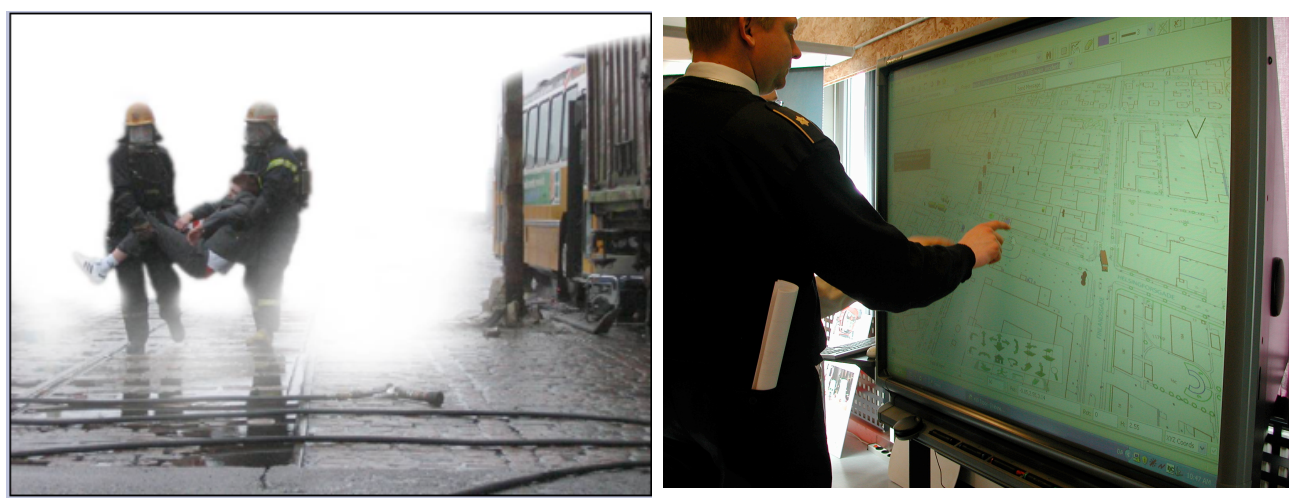

Figure 4. Palcom project - emergency support (Kyng \& Kristensen, 2007)

Emergencies, as in figure 4, are ad-hoc configurations-almost nothing can be expected as regards infrastructure. People's private lives and the work of professionals meet in rather unanticipated ways to say the least. Overview needs to be created and recreated while it is also important to be able to identify and recognise e.g. individual casualties.

\subsection{The individual in the collective}

Life on a Baltic island, as in fig.5, consists of much more than the work in the call centre, with permanent video contact with the other islands ("same" workplace), fishing, cultivating etc., which in our anthropological study is seen to mix in and even take over (Räsänen 2006).

The example in fig.6, designing for a wastewater plant, focuses on multiple forms of interaction. Two examples of how to design technology to fit into the existing multiplicity of actors, artefacts and locations will be discussed. These examples aim to make use of recent techno- 
logical possibilities at the same time as they emphasize the need of the plant workers to move about in the wastewater plant (Bertelsen \& Nielsen 1999; Nielsen \& Søndergaard 2000; Bertelsen \& Bødker 2001).

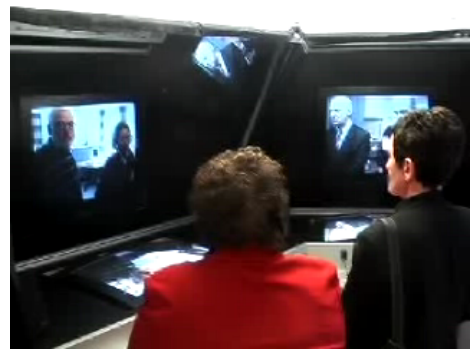

Figure 5. Call centre communication between distant islands
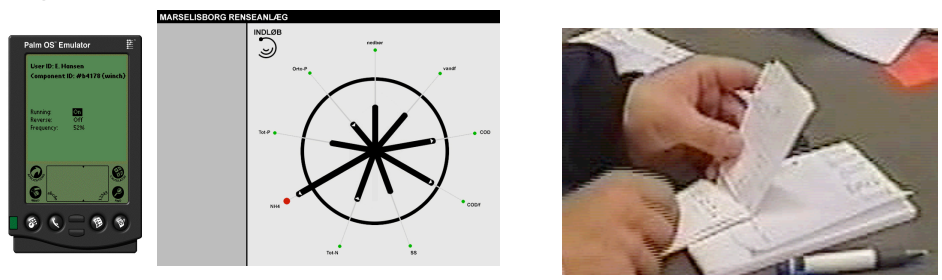

Figure 6. Moving about the wastewater plant

\subsection{Prototyping for understanding problems and possibilities - with all ages}
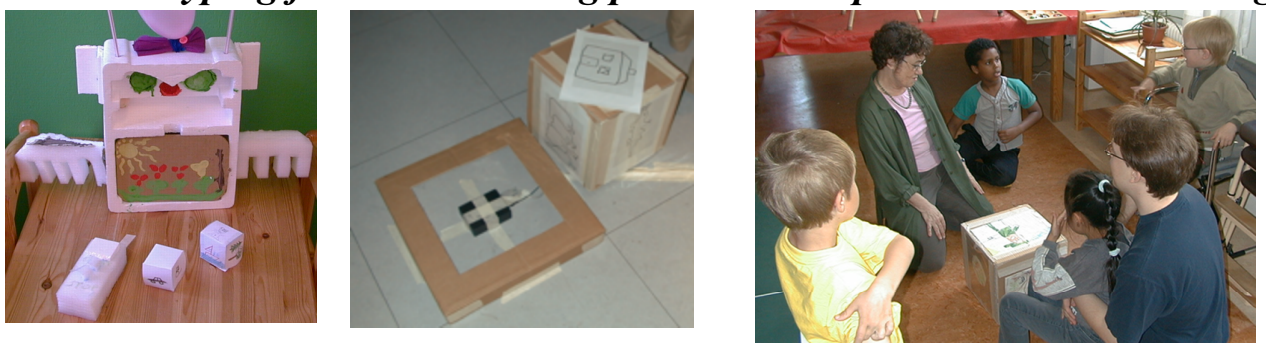

Figure 7. Mock-up and experience of storytelling dice, helping in choosing story subjects.

In the KidStory project (Fig 7), (Taxén \& al 2001; Benford \& al 2000) elementary school children and teachers together with researchers investigated if and how IT could add to storytelling and designed storytelling devices. The process added to everyone's understanding of pros and cons with technology.

Flexible work as a context for IT design challenges the established traditions for what to leave open and what to formalize in interaction design. (Bødker \& Christiansen 2004) present a design approach, where the point of departure was that designers and users from the outset know so little about what might be desirable as regards support for peripheral awareness in an open office setting, where some people are in the office and others work, e.g. from the home. Hence exploratory prototyping was used to help us explore which questions to ask (Fig 8).
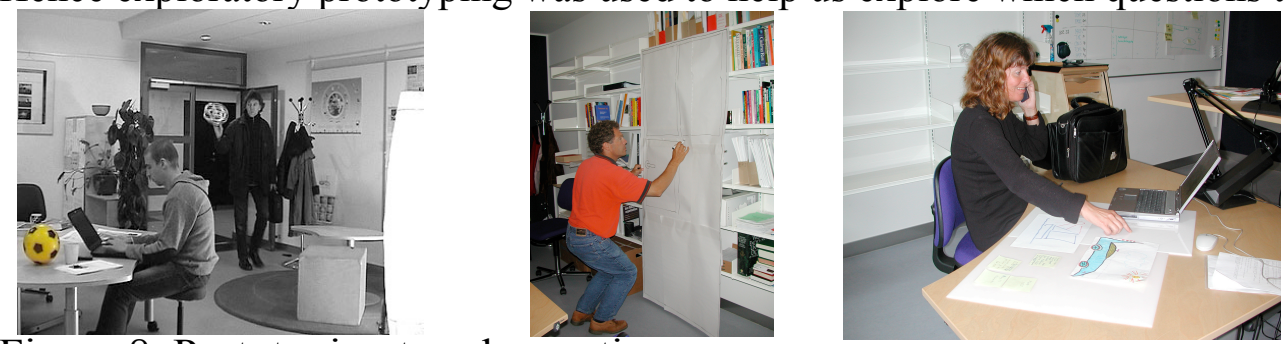

Figure 8. Prototyping to ask questions.

\subsection{Mixing work and daily life}

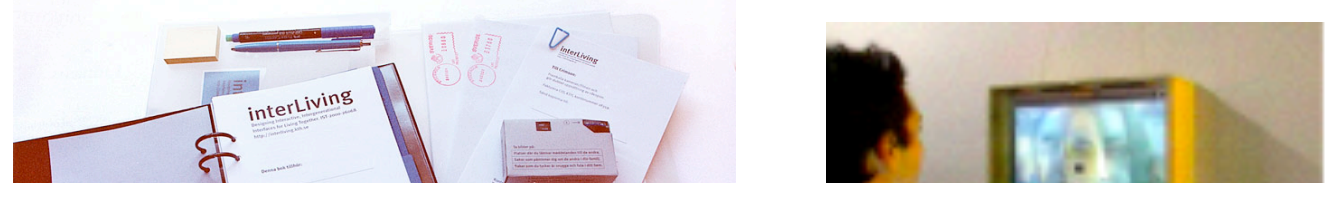


Figure 9. In the interLiving project,cultural probes and technical probes (here a video mirror, mixing local and remote camera) were used for understanding the width of family communication, at home, at work, in school and on the run (Westerlund \& al 2003).

Analysing diaries by all family members during one work week and one holiday week and disposable camera pictures, communication habits and breakdowns were seen, often from all partners involved. One clear problem is different devices for work and leisure.

\subsection{Traditional workplaces, certification, with untraditional user/worker involvement}
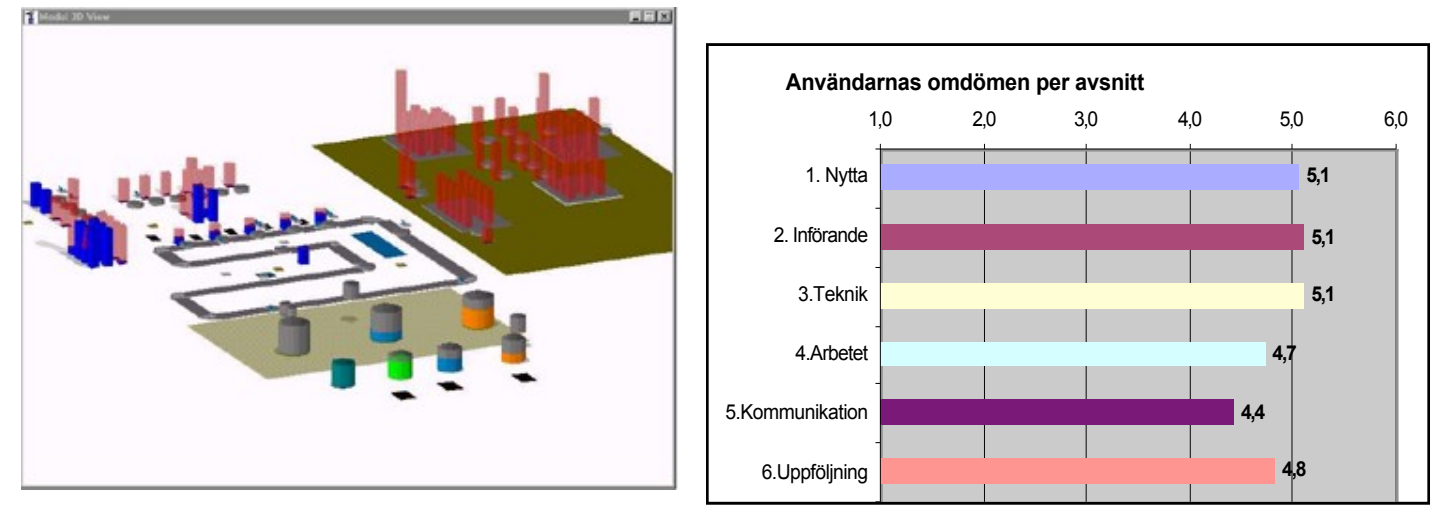

Figure 10. UsersAward, pilot study (simulation) and certification protocol.

With advanced personal computer tools and the internet becoming broadly available the users on the workfloor can be involved in simulations for better understanding of how to plan the daily production (in fig.10 from Arvika foundry) and in communication making user driven certification of workplace software feasible (Walldius \& al 2007; Sundblad \& al 2002).

\section{Discussion}

From the collage and previous discussion we observe how technology move from singular applications to ongoing mixing and configuration of activities, devices and collaborators. Work technologies meet and mix with technology for leisure and everyday life, and new types of possibilities for supporting community, awareness and learning occur.When neither applications nor users are islands the classical usability focus becomes too limited: The third wave of HCI points towards a need for a focus on experience and emotion. Furthermore, it is necessary to explore the many innovative forms of interaction, even at early stages where the purpose of the design is not yet known; it is important to focus on multiple users and uses and on the experience of use. Post-design evaluation is not enough, and in this move towards interaction design, cooperative design has an important role to play.

The ubiquitous role of computing in everyday life makes participation possible but also in some cases a burden. It often seems as if influence as regards non-work technology goes through consumerism and "voting with their feet," at the same time as influence in the workplace has roots in almost forgotten democracy ideas from the 1970's, to some extent manifested in co-determination laws. We propose that these two sides can meet, and the workplace 
democracy revived and more fully pursued, through initiatives like the UsersAward. A Scandinavian perspective should and could move the current co-determination framework outside of work and strengthen people's influence in both arenas.

\section{Acknowledgements}

We thank all research and design partners and users in the many projects mentioned here.

\section{References}

Bannon, L. (1991). From human factors to human actors: The role of psychology and human-computer interaction studies in system design. In Greenbaum, J. \& Kyng, M. (Eds.). Design at Work: Cooperative Design of Computer Systems. (pp. 25-44). Hillsdale, NJ: Lawrence Erlbaum Associates.

Beck, E.E. (2002). P for Political: Participation is Not Enough, Scandinavian Journal of Information Systems, 14(2):77-92.

Benford, S., Bederson, B. B., Åkesson, K-P., Bayon, V., Druin, A., Hansson, P., Hourcade, J. P., Ingram, R., Neale, H., O'Malley, C., Simsarian, K. T., Stanton, D., Sundblad, Y \& Taxén, G. (2000). Designing Storytelling Technologies to Encourage Collaboration Between Young Children. Proceedings of CHI 2000 , the Hague, Netherlands, 556-563.

Bertelsen, O. \& Bødker, S. (2001). Cooperation in massively distributed information spaces. In ECSCW 2001: Proceedings of the Seventh European Conference on Computer Supported Cooperative Work, Bonn, Germany, 16-20 September 2001. Dordrecht: Kluwer Academic Publishers, 1-18.

Bertelsen, O. W. \& Nielsen, C. (1999). Dynamics in Wastewater Treatment: A Framework for Understanding Formal Constructs in Complex Technical Settings. In Proceedings of ECSCW99: Proceedings of the Sixth European Conference on Computer Supported Cooperative Work, 12-16 September 1999, Copenhagen, Denmark. Dordrecht: Kluwer Academic Publishers, 277-290.

Bødker, S. (1996). Creating conditions for participation: Conflicts and resources in systems design, Human Computer Interaction.11:215-236.

Bødker, S. (2006), When second wave HCI meets third wave challenges, NordiCHI keynote. In Mørch, A., Morgan, K., Bratteteig, T., Ghosh, G. \& Svanæs, D. (Eds.). NordiCHI 2006. Proceedings of Fourth Nordic Conference on Human-Computer Interaction (1-8). Oslo: ACM press.

Bødker, S. \& Bøgh Andersen, P. (2005). Complex Mediation, Journal of Human Computer Interaction, 20(4) (353-402).

Bødker, S. \& Christiansen, E. (2004). Designing for ephemarality and prototypicality. Symposium on Designing Interactive Systems Proceedings of the 2004 conference on Designing interactive systems: processes, practices, methods, and techniques. (pp. $255-260$ ). New York, NY: ACM press.

Bødker, S. Ehn, P., Kammersgaard, J., Kyng, M., \& Sundblad, Y. (1987). A Utopian Experience. In Bjerknes, G., Ehn, P., Kyng, M. Computers and Democracy-a Scandinavian Challenge. (pp. 251-278). Aldershot, UK: Avebury.

Bødker, S., Ehn, P., Knudsen, J. L., Kyng, M., \& Madsen, K. H. (1988). Computer Support for Cooperative Design. Proceedings of Conference on CSCW, Portland, Oregon, September 1988 (pp. 377-394), New York, NY: ACM press.

Bødker, S., Ehn, P., Sjögren, D. \& Sundblad, Y (2000): Co-operative Design perspectives on 20 years with the Scandinavian IT Design Model. Invited paper, Proc. NordiCHI2000, Stockholm, Oct 2000.

Bødker, S., Grønbæk, K. \& Kyng, M. (1993). Cooperative Design: Techniques and Experiences from the Scandinavian Scene. In Schuler, D. \& Namioka, A. (Eds.). Participatory design. Principles and practices. (pp. 157-76). Hillsdale, NJ: Lawrence Erlbaum Associates.

Druin, A. (1999). Co-operative Inquiry - Developing New Technology for Children with Children, Proceedings of CHI99, Pittsburgh, May 1999, pp. 223-230.

Dunne, A. \& Raby, F. (2001). Design Noir: The Secret Life of Electronic Objects. Basel, Berlin: Birkhäuser

Ehn, P. \& Kyng, M. (1987). The Collective Resource Approach to Systems Design. In In Bjerknes, G., Ehn, P., Kyng, M. Computers and Democracy-a Scandinavian Challenge. (pp. 17-58). Aldershot, UK: Avebury. 
Ehn, P., \& Kyng, M. (1984). A tool perspective on design of interactive computer support for skilled workers. In M. Sääksjärvi (Ed.), Proceedings from the Seventh Scandinavian Research Seminar on Systemeering. (pp. 211-242). Helsinki: Helsinki Business School.

Greenbaum, J. \& Kyng, M. (eds.). (1991). Design at Work: Cooperative Design of Computer Systems. Hillsdale, NJ: Lawrence Erlbaum Associates.

Groth, K., Lindquist, S., Bogdan, C., Lidskog, T., Sundblad, Y. \& Sandor, 0. (2006). Saxaren - Strengthening Informal Collaboration among Geographically Distributed Teachers. In Proceedings of OzCHI, ACM, Australia, November 2006.

Grønbæk, K., Kyng, M. \& Mogensen, P. (1997). Toward a Cooperative Experimental System Development Approach. Kyng, M. \& Mathiassen, L. (Eds.) Computers and Design in Context. (pp. 201-238). Cambridge, MA: MIT press.

Halskov, K. \& Dalsgård, P. (2006). Inspiration Card Workshops. Carroll, J.M., Bødker, S., Coughlin, J. (Eds.). Proceedings of the Conference on Designing Interactive Systems, University Park, PA, USA, June 26-28, 2006 (pp. 2-11). New York, NY:ACM press.

Hornecker, E. \& Buur, J. (2006). Getting a grip on tangible interaction: a framework on physical space and social interaction. Proceedings of the SIGCHI conference on Human Factors in computing systems, (Montreal, Quebec, Canada, 2006). (437-446). New York: NY:ACM Press.

Hutchinson, H., Mackay, W., Westerlund, B., Bederson, B., Druin, A., Plaisant, C., Beaudouin-Lafon, M., Conversy, S., Evans, H., Hansen, H., Roussel, M., Eiderbäck, B., Lindquist, K. \& Sundblad, Y. (2003): Technology Probes: Inspiring Design for and with Families, Proc. CHI2003, Fort Lauderdale April 2003.

Kensing, F., Simonsen, J. \& Bødker, K. (1998). MUST: A Method for Participatory Design. Human-Computer Interaction 13(2):167-198.

Kristensen, J. F., Eriksen, M. A., Iversen, O. S., Kanstrup, A. M., Nielsen, C. \& Petersen, M. G. (2003). Young People In Old Cars - Challenges For Cooperative Design. I Proceedings of the the 26th Information Systems Research Seminar in Scandinavia (IRIS 26).

Kyng, M. and Kristensen, M. (2007). Supporting Palpability in Emergency Response. Designing for palpability Workshop at Pervasive 2007, May 13th-16th 2007. Toronto, Canada.

Kyng M. (1995). Creating Contexts for Design. In Carroll, J. M. (Ed.), Scenario-based design. Envisioning work and technology in system development. (pp. 85-108). New York, NY: Wiley.

Mackay, W.E., Ratzer, A.V. \& Janecek, P. (2000): Video artefact for design: bridging the gap between abstraction and detail. Proc. of ACM DIS 2000, ACM Press, pp.72-82.

McCarthy, J. \& Wright, P. (2004). Technology as experience. Cambridge, MA: MIT Press.

Nielsen, M.N. \& Bødker, S. (2004). Desktop Computing, Australian Journal of Information Systems, pp. 88-101.

Nielsen, C. \& Søndergaard, A. (2000). Designing for mobility: an integration approach to support mobile technologies. NordiCHI 2000 Proceedings, CD-ROM.

Petersen, M. G. (2004) Remarkable Computing - the Challenge of Designing for the Home. In Proceedings of CHI'2004, ACM Press, pp. 1445-1449.

Räsänen, M. (2006): Islands of Togetherness: Rewriting Context Analysis. Doctoral thesis, TRITA-CSC-A 2006 : 29, Royal Institute of Technology, School CSC, December 2006.

Sundblad, Y., Lind, T. \& Rudling, J. (2002): IT product requirements and certification from the users' perspective, Proc. WWDU'2002, pp.xx-yy, Bavaria May 2002.

Taxén, G., Druin, A., Fast C. \& Kjellin, M (2001). KidStory: A technology design partnership with children. Behaviour \& Information Technology, Vol. 20:2, April 2001, 119-125

Walldius, Å., Sundblad, Y., Sandblad, B. Bengtsson, L. \& Gulliksen, J. (2007): User certification of Workplace Software - Assessing both Artefact and Usage, to appear in BIT 2007, 25 pages.

Westerlund, B., Lindqvist, K., Mackay, W. \& Sundblad, Y. (2003). Co-designing methods for designing with and for families. Proc. 5th European Academy of Design Conference, Barcelona, April 2003. 